Available online at https://jurnal.stmikroyal.ac.id/index.php/jurdimas

\title{
PELATIHAN PENGGUNAAN EJAAN YANG DISEMPURNAKAN DAN \\ KALIMAT EFEKTIF PADA PENULISAN SURAT RESMI BAGI KURSUS BINTANG MULIA BATU BARA DESA PEMATANG RAMBAI KECAMATAN NIBUNG HANGUS KABUPATEN BATU BARA
}

\author{
Sri Rezki Maulina Azmi*, Muthia Dewi , Akmal \\ Sistem Informasi, STMIK Royal \\ email: srirezki.maulina@yahoo.com*
}

\begin{abstract}
Abstrack: Indonesian for the Indonesian nation is the language of unity. Indonesian is also a communication tool for all Indonesian people. Therefore, Indonesian language learning is devoted to improving the ability of students to communicate using Indonesian language properly and correctly verbally or in writing. The community service activity entitled "Training on the Use of Enhanced Spelling and Effective Sentences on Writing Official Letters for the Bintang Mulia Coal Course in Pematang Rambai Village, Nibung Hangus District, Batu Bara District" aims to train students in the Guidance for Bintang Mulia Coal Village Pematang Rambai properly and correctly. The method used in this conventional activity is material exposure, discussion, and practice. The speaker conducts explanations about the use of improved spellings and arguments effectively in writing official letters.
\end{abstract}

Keywords: Use of Enhanced Spelling and effective sentences on official letter writing

\begin{abstract}
Abstrak: Bahasa Indonesia bagi bangsa Indonesia adalah bahasa persatuan. Bahasa Indonesia juga sebagai alat komunikasi bagi seluruh rakyat Indonesia. Oleh karena itu, pembelajaran bahasa Indonesia dikhususkan untuk meningkatkan kemampuan peserta didik agar berkomunikasi menggunakan bahasa Indonesia dengan baik dan benar secara lisan maupun tulis. Kegiatan pengabdian kepada masyarakat yang diberi judul "Pelatihan Penggunaan Ejaan Yang Disempurnakan Dan Kalimat Efektif Pada Penulisan Surat Resmi Bagi Kursus Bintang Mulia Batu Bara Desa Pematang Rambai Kecamatan Nibung Hangus Kabupaten Batu Bara" bertujuan untuk melatih peserta didik yang ada padabimbingan kursus Bintang Mulia Batu Bara Desa Pematang Rambai dengan baik dan benar. Metode yang digunakan dalam kegiatan ini konvensional yaitu paparan materi, diskusi, dan latihan. Pemateri melakukan penjelasan-penjelasan tentang penggunaan ejaan yang disempurnakan dan dalimat efektifpada penulisan surat resmi.
\end{abstract}

Kata kunci: Penggunaan Ejaan Yang Disempurnakan dan kalimat efektif pada Penulisan surat resmi 
Jurdimas (Jurnal Pengabdian Kepada Masyarakat) Royal

Vol. 2 No. 1, Jan 2019, hlm. 75 - 78

ISSN 2614-7912 (Print)

DOI: https://doi.org/10.33330/jurdimas.v2i1.326

ISSN 2622-3813 (Online)

Available online at https://jurnal.stmikroyal.ac.id/index.php/jurdimas

\section{PENDAHULUAN}

Bahasa Indonesia mempunyai kedudukan sebagai bahasa nasional dan bahasa Negara. Oleh karena itu, bahasa Indonesia berfungsi sebagai bahasa pengantar di lembagalembaga pendidikan, sebagai lambang kebanggaan nasional, sebagai alat penyatu berbagai suku bangsa dengan latar belakang sosial budaya dan bahasa dan sebagai pengembang kebudayaan, ilmu pengetahuan dan teknologi, serta sebagai alat perhubungan dalam kepentingan pemerintahan dan kenegaraan.

Bahasa adalah salah satu alat yang dipergunakan sebagai komunikasi. Bahasa pada hakikatnya bersifat kemanusiaan, walaupun mungkin tidak terbatas pada manusia. Hal tersebut terjadi karena sebagai makhluk sosial, manusia selalu berkomunikasi dengan orang lainsebagai wujud interaksi dalam pergaulan.

Bahasa Indonesia memiliki ragam lisan dan tulisan yang keduaduanya dapat digunakan di dalam situasi formal (resmi) dan situasi tak resmi.. Pengajaran bahasa Indonesia pada hakikatnya adalah pengajaran keterampilan berbahasa, bukan pengajaran tentang bahasa. Tata bahasa, kosakata, dan sastra disajikan dalam konteks, yaitu dalam kaitannya dengan keterampilan tertentu yang tengah diajarkan, bukan sebagai pengetahuan. Tata bahasa teori pengembangan kosakata, teori sastra sekedar sebagai pendukung atau alat penjelas.

Keterampilan - keterampilan berbahasa yang perlu ditekankan adalah keterampilan reseptif (menyimak dan membaca) dan keterampilan produktif (menuturkan dan menulis). Pengajaran bahasa diawali dengan pengajaran keterampilan reseptif, keterampilan produktif dapat ikut ditingkatkan. Fungsi bahasa yang utama adalah sebagai alat komunikasi.

Di dalam pengajaran, bahasa disajikan secara bermakna sebagai suatu keutuhan, yaitu dalam konteks penggunaannya pada komunikasi, bukan sebagai butir yang terpotongpotong. Sebab, dalam berkomunikasi kalimat yang digunakan bukan kalimat yang terpotong-potong, melainkan kalimat yang saling berkaitan dan bermakna. Bahasa merupakan salah satu hasil kebudayaan yang harus dipelajari dan diajarkan. Dengan bahasa, kebudayaan suatu bangsa dapat dibentuk, dibina dan dikembangkan serta dapat dituntunkan kepada generasi-generasi mendatang.

Selain itu, pembelajaran bahasa bertujuan untuk meningkatkan kemampuan berpikir dan bernalar, untuk meningkatkan kemampuan wawasan dan keterampilan berbahasa. Pembelajaran bahasa Indonesia diarahkan untuk meningkatkan kemampuan siswa dalam berkomunikasi dengan bahasa Indonesia baik secara lisan maupun tertulis. Komponen terpenting dalam berkomunikasi adalah keterampilan menulis surat. Surat adalah suatu sarana komunikasi yangdigunakan untuk menyampaikan informasi tertulis oleh suatu pihakkepada pihak lain. Informasi yangdisampaikan itu dapat berupa pengetahuan, pernyataan, perintah, permintaan atau laporan". contoh: menulis surat pribadi, surat dinas dansurta niaga. 
Available online at https://jurnal.stmikroyal.ac.id/index.php/jurdimas

Melalui surat, segala bentuk informasi dapat disampaikan kepada pembaca dalam bentuk tertulis. Agar tidak terjadi kesalahpahaman antara penulis dan pembaca mengenai isi surat, maka penulisan bagian-bagian surat harussesuai dengan kaidah bahasa dan kalimat efektif. Melalui pemakaian kalimat efektif dalam surat menyurat, pesan yang disampaikan dalam surat ituakan mudah dipahami dan tergambar jelas dalam pikiran pembaca surat.

Bentuk kegiatan ini dilakukan dengan cara menyampaikan materi dalam bentuk ceramah dan penjelasan menggunakan power point. Kegiatan pengabdian kepada masyarakat dilaksanakan di Desa Pematang Rambai Kecamatan Nibung Hangus Kabupaten Batu Bara.Kegiatan pengabdian kepada masyarakat dilaksanakan pada tanggal 21-22Desember 2018, mulai pukul 09.00 WIB s/d Selesai.

\section{METODE}

Hakikat surat resmi, penggunaan Ejaan yang disempurnakan, dan penggunaan kalimat efektif dalam surat resmi.

Metode yang digunakan dalam pelatihan ini ada dua cara, yaitu penyampaian materi dan latihan. Penguraian materi mulai dari pengenalan tentang Ejaan Yang Disempurnakan, kalimat efektif, surat resmi dan menjelaskan 1 contoh surat resmi. Sedangkan metode latihan, peserta didik diarahkan mengikuti langkahlangkah yang diajarkan oleh narasumber. Beberapa instruktur membantu peserta didik jika mengalami kesulitan. Contoh surat yang diberikan dalam latihan kepada peserta didik adalah contoh surat resmi berupa surat pernikahan.

\section{PEMBAHASAN}

Hasil dari kegiatan pengabdian kepada masyarakat yang telah dilakukan pada peserta didik kursus Bintang Mulia Batu Bara dapat diuraikan sebagai berikut:

1. Peserta mengikuti kegiatan ini mulai dari awal sampai dengan selesai. Sesi pertama adalah dengan menjelaskan materi yang berkaitan penggunaan Ejaan yang disempurnakan, dan penggunaan kalimat efektif dalam surat resmi.

2. Peserta yang mengikuti kegiatan ini sebanyak 26 orang, terdiri dari mentor-mentor dan peserta didik.

3. Dari hasil latihan yang dilakukan, peserta didik dapat memahami dan sudah mampu menulis surat resmi berdasarkan penggunaan ejaan yang disempurnakan dan penggunaan kalimat efektif dalam surat resmi.

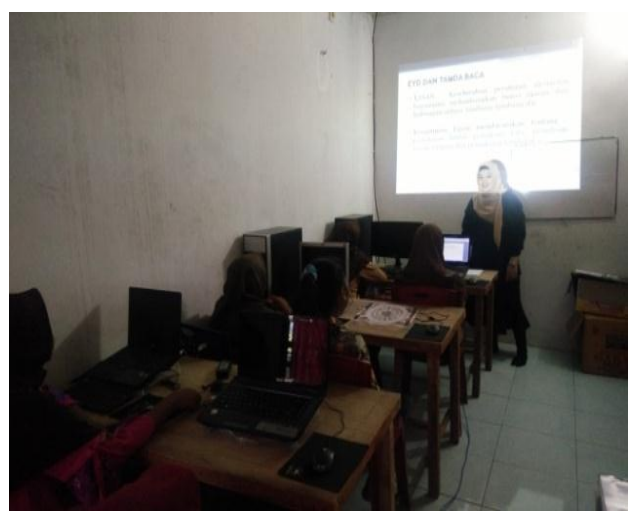

Gambar 1. Penyampaian Materi 
Available online at https://jurnal.stmikroyal.ac.id/index.php/jurdimas

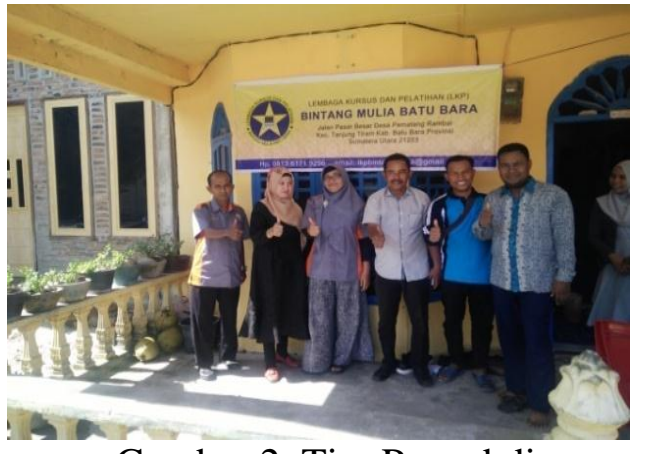

Gambar 2. Tim Pengabdian

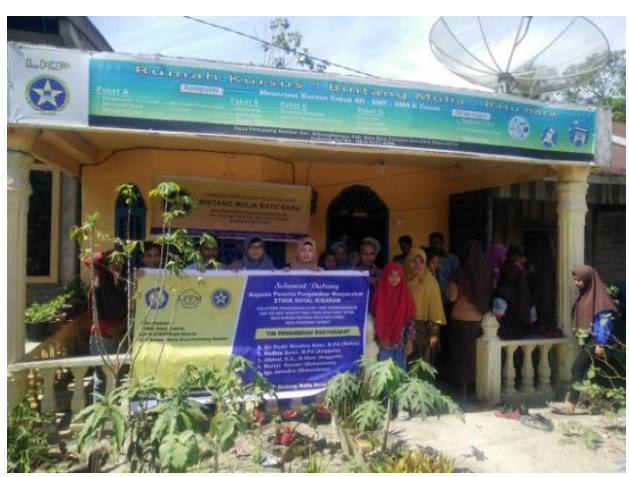

Gambar 3. Tim Pengabdian

\section{SIMPULAN}

Dari pembahasan pada bab-bab sebelumya, kegiatan pengabdian kepada masyarakat ini dapat disimpulkan:

1. Pengabdian kepada mayarakat dilakukan pada kursus di Bintang Mulia Batu Bara Jumlah peserta dalam kegiatan ini 30 orang, terdiri dari mentor-mentor dan peserta didik.

2. Tujuan dan manfaat dari kegiatan ini sudah tepat pada sasaran. Sehingga bekal ilmu pengetahun tentang penggunaan ejaan yang disempurnakan dan kalimat efektif pada penulisan surat resmi dapat diimplementasikan dalam mendukung pembelajaran kursus di Bintang Mulia Batu Bara. Selain itu, hubungan antara manajemen
STMIK Royal dengan kursus di Bintang Mulia Batu Bara terjalin dengan baik, sehingga dapat melanjutkan ke program kerja sama antara lembaga kursus daninstitusi.

3. Ada dua sesi yang dilakukan pada kegiatan ini, pertama sesi penyampaian materi dan selanjutnya masuk ke sesi latihan. Pada sesi latihan, peserta didik dibantu oleh instruktur untuk memudahkan peserta didik lebih memahami dan bisa menulis surat.

\section{DAFTAR PUSTAKA}

Machfudz, Imam. 2000. Metode Pengajaran Bahasa IndonesiaKomunikatif. Jurnal Bahasa dan Sastra UM

Moeleong, Lexy J. 2000. Metodologi Penelitian Kualitatif. Bandung: PT. Remaja Rosyda Karya.

Rahardi, Kunjawa. 2009. Bahasa Indonesia untuk Perguruan Tinggi. Jakarta : Penerbit Erlangga

Saksomo, Dwi. 1983. Strategi Pengajaran Bahasa Indonesia. Malang: IKIP Malang

Salamun, M. 2002. Strategi Pembelajaran Bahasa Arab di Pondok Pesantren. Tesis.. Tidak diterbitkan

Sholhah, Anik. 2000. Pertanyaan Tutor dalam Pembelajaran Bahasa Indonesia untuk Penutur Asing di UM. Skripsi. Tidak diterbitkan. 